\title{
In memoriam Hans Heinrich Pässler 1940-2018
}

\author{
Rainer Siebold ${ }^{1,2}$
}

Received: 22 March 2018 / Accepted: 18 April 2018 / Published online: 27 April 2018

(c) European Society of Sports Traumatology, Knee Surgery, Arthroscopy (ESSKA) 2018

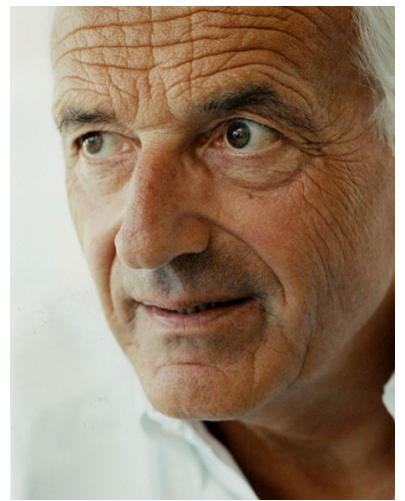

Hans Pässler was one of the greatest visionaries in the field of knee surgery. He was an exceptionally friendly, courteous person, and one of the most open characters I ever met. He was a philanthropist and an optimist; he had endless energy and remarkable ideas and was very valued by patients, colleagues, and friends.

Hans Pässler was born on 14 July 1940 in Dresden, Germany. His father was a professor, specialising in angiology at the hospital in Leverkusen. Hans followed in his father's footsteps and studied medicine at the University of Kiel from 1961 to 1967 . Fascinated by his first clinical experience at the Ludolf-Krehl University Hospital in Heidelberg, he was awarded a fellowship under the famous Professor Michael DeBakey in cardiovascular surgery at the University of Houston, Texas. He was extremely impressed by the surgical skills of DeBakey and planned to become a cardiovascular surgeon himself. However, back home, he continued his

Rainer Siebold

rainer.siebold@atos.de

1 HKF-International Center for Hip-Knee-Foot Surgery, ATOS Clinic, ATOS Hospital Heidelberg, Bismarckstrasse 9-15, 69115 Heidelberg, Germany

2 Institute for Anatomy and Cell Biology, Ruprecht-Karls University, INF, Heidelberg, Germany medical residency at the University Hospital for Trauma Surgery in Ulm under Professor Burri. Supported by Professor Burri, he pursued his interest in trauma and knee surgery and developed the concept of the early functional postoperative rehabilitation following the reconstruction of knee ligaments [2]. Inspired by his clinical and scientific work, he became a trauma surgeon.

For 14 years, he was head of trauma surgery and medical director at the hospital in Bopfingen. During this time, he specialised further in arthroscopic knee surgery and eventually became one of the most experienced ACL surgeons in Germany and worldwide.

He performed hundreds of ACL reconstructions every year and developed his own technique of implant-free ACL reconstruction [3]. His experience, friendly attitude, and open mindedness made him one of the most frequently invited speakers at international meetings for many years. Many international colleagues and knee specialists found their way to Bopfingen and later to the ATOS Hospital in Heidelberg to share his experience.

In 1986, Hans became Vice President of the Collège Européenne de Traumatologie du Sport (CETS). He was also one of the founder members of the European Federation of National Societies for Orthopedic Sportsmedicine (EFOST).

Hans was the true visionary of the modern ATOS Hospital in Heidelberg. Back in 1985, he was convinced that joint specialisation was advantageous for patients. In 1993, at the ATOS Hospital, he focused on arthroscopic knee surgery and asked the shoulder specialist, Professor Peter Habermeyer, to join him in establishing an ATOS shoulder department. The first highly specialised private orthopedic hospital in Germany was born. Hans was its medical director from the start.

Hans Pässler was an internationally highly respected gentleman who travelled around the globe for scientific meetings and to meet colleagues and friends. He was a visiting professor at the Department of Orthopaedic Surgery, University of Pittsburgh (Prof. Fu), the University of Ioannina (Prof. Soukakos), the Chinese General Hospital PLA Beijing (Prof. Wang), the University of Athens (Prof. Soukakos), 
and the University of Perugia (Prof. Cerulli), to name but a few. He was also a member of many international advisory boards. Hans was on the Editorial Board of the European Journal of Orthopaedic Surgery \& Traumatology, Sportorthopädie-Sporttraumatologie, Actualités Sport et Médicine, Bordeaux, the Bulgarian Journal of Orthopaedics and Traumatology, Acta Clinica, Poland, the Chinese Journal of Minimally Invasive Surgery, Revista Traumatologia del Deporte, Spain, the Chinese Journal of Orthopaedic Trauma (Overseas Editor), and the Journal of Orthopaedic ScienceOfficial Journal of the Japanese Orthopaedic Association. He was also a member of the American Academy of Orthopaedic Surgeons, the Anterior Cruciate Ligament (ACL) Study Group, the American Orthopaedic Research Society (ORS), the International Society of Arthroscopy, Knee Surgery and Orthopaedic Sports Medicine (ISAKOS), and the European Society for Sports Traumatology, Knee Surgery and Arthroscopy (ESSKA).

He was the organiser and host of many Heidelberg ATOS Knee Courses and initiator of the first worldwide live Internet transmission of an arthroscopic ACL reconstruction on 28 March 1996. He was also the author of several books [4] on arthroscopic knee surgery and many scientific peerreviewed publications, very often in international co-operation [1]. He shared his knowledge not only with colleagues but also with numerous international young people from Europe and all over the world. In 1997, he started on ongoing co-operation together with the Hellenic Sports Medicine community.

Hans Pässler was invited to take part in many TV interviews and produced numerous educational videos of surgical techniques. In 2011, he initiated a website at which patients can obtain a "second opinion" before surgery to reconfirm the indication. His intention was to reduce the number of unnecessary interventions.

Hans was always an enthusiast and he loved his profession. He enjoyed life, he was a cosmopolitan gentleman, and he was always eager to learn and teach new details of knee surgery. He was full of sparkling ideas, a fascinating man and always cheerful.

His passing is a huge loss for all of us, as well as for his family. He will be in our hearts forever as a friend and special human being. We will treasure his memory.

On behalf of the scientific society and all his friends, we thank him for his huge contributions to our field of knee surgery and for his wonderful friendship.

\section{Compliance with ethical standards}

Conflict of interest The author(s) declare that they have no competing interests.

Ethical approval This article does not contain any studies with human patricipants or animals performed by any of the authors.

Informed consent For this type of study informed consent is not required.

\section{References}

1. Cameron ML, Fu FH, Paessler HH, Schneider M, Evans CH (1994) Synovial fluid cytokine concentrations as possible prognostic indicators in the ACL-deficient knee. Knee Surg Sports Traumatol Arthrosc 2(1):38-44

2. Paessler HH, Deneke J, Dahners LE (1992) Augmented repair and early mobilization of acute anterior cruciate ligament injuries. Am J Sports Med 20(6):667-674

3. Paessler HH, Mastrokalos DS (2003) Anterior cruciate ligament reconstruction using semitendinosus and gracilis tendons, bone patellar tendon, or quadriceps tendon-graft with press-fit fixation without hardware. A new and innovative procedure. Orthop Clin North Am 34(1):49-64

4. Pässler HH (2003) New techniques in knee surgery. Steinkopff, Heidelberg 